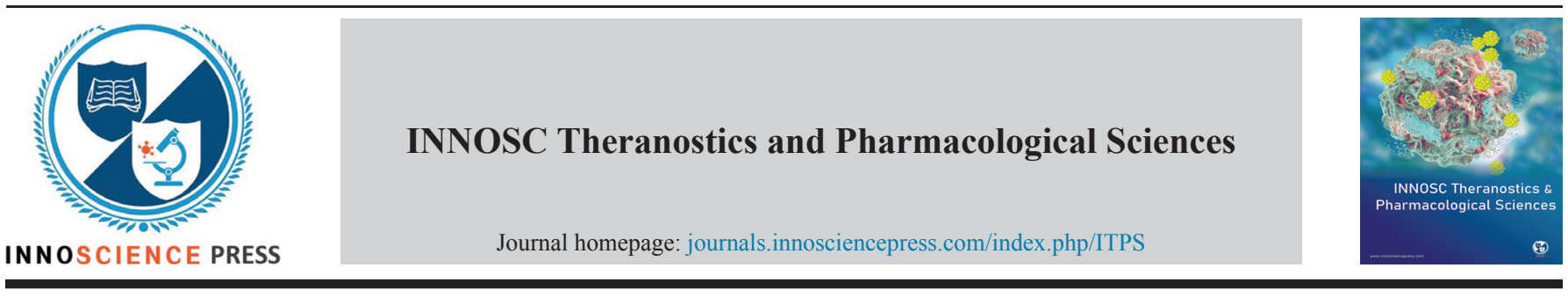

ORIGINAL ARTICLE

\title{
Community Pharmacy Services During the COVID-19 Pandemic: A Systematic Review
}

\author{
Ana Mendonça ${ }^{1,2}$, Cátia Santos ${ }^{1,2}$, Isabel C. Pinto $2,3,4 *$ \\ ${ }^{1}$ Health School, Polytechnic Institute of Bragança, Bragança, Portugal \\ ${ }^{2}$ Department of Diagnostic and Therapeutic Technologies, Health School, Polytechnic Institute of Bragança, Bragança, Portugal \\ ${ }^{3}$ Polytechnic Institute of Bragança, Bragança, Portugal \\ ${ }^{4}$ Centro de Investigação de Montanha (CIMO), Instituto Politécnico de Bragança, Campus de Santa Apolónia, 5300-253 Bragança, Portugal \\ *Correspondence Author: Isabel C. Pinto, Email: isabel.pinto@ipb.pt
}

Received: October 14, 2020; Accepted: November 23, 2020; Published: December 21, 2020 DOI: 10.36922/itps.v3i2.971

Copyright: $($ C) 2020 Mendonça, et al. This is an open-access article distributed under the terms of the Creative Commons AttributionNonCommercial 4.0 International 4.0 (CC BY-NC 4.0), which permits all non-commercial use, distribution, and reproduction in any medium, provided the original work is properly cited.

\begin{abstract}
:
Background. As a central part of the healthcare system, the community pharmacies are afflicted by the repercussions of the pandemic. Therefore, they have to adapt their services according to the needs of their communities.

Objective. This article presents a systematic review with the aim to identify the additional services that community pharmacies are providing during the COVID-19 pandemic.

Methods. The PubMed, Web of Science, and ScienceDirect databases were searched systematically for relevant articles between December 2019 and April 2020, using "Community Pharmacy," "Services," "COVID-19," "Coronavirus," and "Pandemic" as the keywords. Fifty-nine articles in English, Portuguese, or Spanish were obtained and after applying the filtering criteria, nine of them were selected and included in the study.

Results. Community pharmacies should provide pharmaceutical services that are according to the needs of the communities. During the COVID-19 pandemic, changes of these services must be in line with the common goal of preventing the spread of the disease. In addition to the pre-existing services such as medication dispensing and personalized care, community pharmacists must promote other types of services, for example, informing, advising, and educating the community, maintaining a stable supply of pharmaceuticals and health products, and screening of suspected cases.

Conclusion. While remaining engaged in the coordinated efforts, community pharmacists should apply innovations in their practices to help prevent the spread of coronavirus.
\end{abstract}

Keywords: Community pharmacy, Services, COVID-19, Pandemic, Coronavirus

\section{Introduction}

Coronaviruses belong to a large family of RNA viruses that were initially discovered in domestic birds. They cause respiratory, gastrointestinal, liver, and neurological diseases in animals, and only six viruses of this family cause disease in humans. It is known that two of these six species, namely the severe acute respiratory syndrome-related coronavirus (SARS-CoV) and Middle East respiratory syndrome-related coronavirus, cause acute respiratory syndrome with high mortality rates $[1,2]$.

SARS-CoV-2 is the new type of coronavirus that was first identified in humans in late 2019, in Wuhan, China. SARS-CoV-2 causes coronavirus disease 2019 (COVID-19) with symptoms associated with pneumonia. Given 
its high contagiousness rate, COVID-19 quickly spread throughout the world and was considered a pandemic by the World Health Organization in March 2020 [2]. COVID-19 is transmitted through respiratory droplets and by direct or indirect contact with a contaminated surface or object. The severity of the signs or symptoms can vary, from asymptomatic to the most severe ones. The most frequent symptoms include fever, cough, and breathing difficulty. However, other less frequent symptoms may also appear such as sore throat, runny nose, headache, and myalgia $[3,4]$.

There is currently no vaccine or any approved or recommended treatment for COVID-19. Therefore, basic therapeutic approaches used for the common cold would be effective in the case of these symptoms. For example, ibuprofen, naproxen, or other nonsteroidal anti-inflammatory drug are used in cases of fever, headache, myalgia, and sore throat; dextromethorphan and codeine are used for cough; and antihistamines (e.g., diphenhydramine, loratadine, fexofenadine, and cetirizine) are used for runny nose [4,5].

The COVID-19 pandemic is currently putting huge pressure on all businesses, especially the healthcare systems worldwide. As a central part of the healthcare system, the community pharmacies are also adversely affected by the repercussions of this pandemic. Particularly, the normal provision of medications has been severely obstructed. Therefore, the activity of the community pharmacies has begun increasingly focusing on the development of support services for their patients [6].

In fact, the community pharmacies have a privileged position to provide services, such as therapy management, administration of medication, setting physiological parameters, identification of people at risk, early detection of several diseases, and promotion of healthier lifestyles. In addition to pharmaceutical interventions for patients with chronic diseases such as hypertension, diabetes, and asthma, the community pharmacies play a role in ensuring the patients with fever, cough, diarrhea, obesity, and on smoking cessation program to adhere to therapy [7].

Since the COVID-19 pandemic is affecting all businesses, especially the healthcare systems worldwide $[6,8]$, the community pharmacies have to adapt their services according to the needs of their community during this pandemic. Therefore, we performed a systematic review to identify the additional services provided by the community pharmacists during the COVID-19 pandemic.

\section{Methods}

A systematic literature review was carried out following an ordered set of criteria that determine the scientific quality of a systematic literature review with the following components: Review question, inclusion and exclusion criteria, strategies for investigating the research universe, guidance for material selection, analysis, and data synthesis [9]. The systematic review was performed and written using the PRISMA guidelines. A flowchart regarding the literature search and selection is presented in Figure 1.

A literature search was conducted in the PubMed, Web of Science, and ScienceDirect databases to look for articles published from December 2019 to April 2020. All present in the five medical subject headings terms were used as the search terms: "Community Pharmacy," "Services," "COVID-19," "Coronavirus," and "Pandemic." The preliminary set of articles was selected based on the following criteria:

- Publications from December 2019 to April 2020, with the combination of the aforementioned keywords in English, were selected;

- Presence of full-text research articles written in English, Portuguese, and Spanish was selected;

- Articles that were identified as duplicates of the screened items or did not have a direct relationship with the topic or not possible to access the full article were excluded from the study.

Based on these criteria, 59 articles were found. These articles were perused by two examiners independently. Seven of them were excluded because they were duplicates and 35 of them were excluded for not being related with the objective of the study in two aspects - title and abstract. Among these 35 articles that were excluded, the article titles of 23 items and the abstracts of 12 items are not in line with the objective of this systematic review. In addition, three items were excluded at this stage because no full texts were available.

The 14 articles that had passed the first screening or met the eligibility criteria were fully analyzed by 


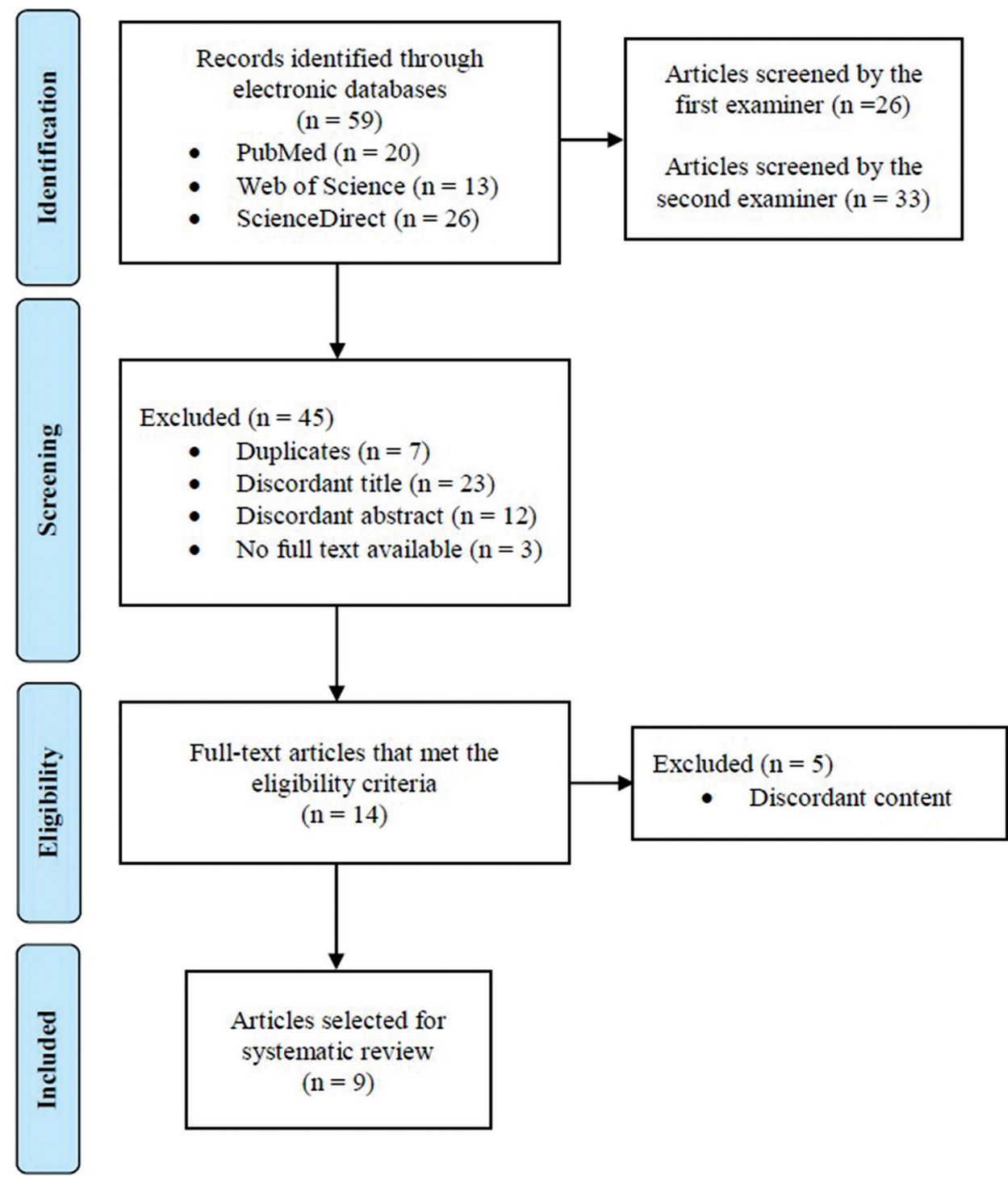

Figure 1. Flowchart of the literature search and selection.

two examiners and 5 of them were also excluded because their contents were not concordant with the objective of this systematic review. The remaining nine articles were then included for the systematic review. They were characterized according to the type of article, authors, publication year, study location, and their respective results in a summary table (Table 1) [9].

\section{Results and discussion}

In total, 9 articles were selected, whose characterization is shown in Table $\mathbf{1}$.

Community pharmacies have a unique responsibility for the health and well-being of people around the world because they are the first and the last points of contact with the patients within the healthcare system. They play a key part in ensuring that healthcare is accessible and patient-centered $[4,7,8]$.

\subsection{Before the COVID-19 pandemic}

Before pandemic, the roles of the community pharmacies are to improve public health through education, provide patient and medication counseling, provide immunizations, educate on infection prevention and control, and supply medication, over-the-counter (OTC) medicines, supplements, and health devices.

\subsubsection{Health education}

Pharmacists play a crucial part in promoting and maintaining their patients' health. The health 
Table 1. Summary table included literature.

\begin{tabular}{|c|c|c|c|c|}
\hline Title & $\begin{array}{l}\text { Authors/ } \\
\text { publication } \\
\text { year }\end{array}$ & $\begin{array}{l}\text { Study } \\
\text { location }\end{array}$ & $\begin{array}{l}\text { Article } \\
\text { type }\end{array}$ & Services during COVID-19 \\
\hline $\begin{array}{l}\text { Community pharmacists: } \\
\text { On the frontline of health } \\
\text { service against COVID-19 } \\
\text { in LMICs [8] }\end{array}$ & $\begin{array}{l}\text { Hedima et al. } \\
\text { April } 2020\end{array}$ & Nigeria & $\begin{array}{l}\text { Review } \\
\text { article }\end{array}$ & $\begin{array}{l}\text { - Avoiding the regional or national shortage of } \\
\text { medication } \\
\text { - Sharing the information on medication availabilities } \\
\text { and its store locations online or through mobile } \\
\text { applications (APPs) } \\
\text { - Arranging mail orders and home delivery services } \\
\text { for the patients who are not able to visit the } \\
\text { community pharmacies } \\
\text { - Maintaining adherence to treatments regimens }\end{array}$ \\
\hline $\begin{array}{l}\text { Pharmacy emergency } \\
\text { preparedness and response } \\
\text { (PEPR) framework for } \\
\text { expanding pharmacy } \\
\text { professionals' roles and } \\
\text { contributions to emergency } \\
\text { preparedness and response }\end{array}$ & $\begin{array}{l}\text { Aruru et al. } \\
\text { April } 2020\end{array}$ & USA & $\begin{array}{l}\text { Review } \\
\text { article }\end{array}$ & $\begin{array}{l}\text { - Volunteering } \\
\text { - Ensuring adequate supply of essential medication } \\
\text { - Promoting the practices of infection control and } \\
\text { disinfection } \\
\text { - Dispensing and administering medication outside } \\
\text { community pharmacies at the points of dispensing } \\
\text { (POD) }\end{array}$ \\
\hline
\end{tabular}

during the COVID-19

pandemic and beyond [10]

Medication management

Kretchy et al. Ghana

and adherence during

April 2020

the pandemic covid-19:

Perspectives and

experiences from low-

and middle-income

countries [11]

Pharmacists' readiness to

deal with the pandemic

coronavirus: Assessing

awareness and perception

of roles [12]

Recommendations and

Zheng et al. China guidance for providing March-20

Review - Promoting the concept of rational medication use

article $\quad$ Preventing, identifying, and resolving medication problems

- Providing appropriate medication information and counseling on the chronic use of medication

Basheti et al. Jordan April 2020

Research - Ensuring the stable supply of key medications

article Providing information about COVID-19

- Performing early detection of diseases and appropriate referral

- Providing patient education

- Educating on infection control and hygiene practices to reduce the spread of infection

pharmaceutical care

services during COVID-19

pandemic: A china

perspective [13]

article

- Providing basic information about COVID-19, including prevention knowledge provide professional knowledge on medication use

- Ensuring adequate supply of medication and products for COVID-19 prevention

- Ensuring safe and efficient environment control, staff protection, and emergency plan establishment

- Providing services through phones, mobile APPs, and internet

- Arranging home delivery of medications

- Providing therapeutic substitution during inadequacy of prescription medication

- Identifying suspected cases of COVID-19 based on clinical symptoms

- Educating the patients in the community on management of chronic diseases, self-monitoring of diseases, and disease control

- Promoting patient's mental health by encouraging them to maintain regular work and physical exercise 
Table 1. (Continued)

\begin{tabular}{|c|c|c|c|c|}
\hline Title & $\begin{array}{l}\text { Authors/ } \\
\text { publication } \\
\text { year }\end{array}$ & $\begin{array}{l}\text { Study } \\
\text { location }\end{array}$ & $\begin{array}{l}\text { Article } \\
\text { type }\end{array}$ & Services during COVID-19 \\
\hline $\begin{array}{l}\text { Community pharmacist in } \\
\text { public health emergencies: } \\
\text { Quick to action against the } \\
\text { coronavirus 2019-nCoV } \\
\text { outbreak [7] }\end{array}$ & $\begin{array}{l}\text { Ung. } \\
\text { February-20 }\end{array}$ & Macao & $\begin{array}{l}\text { Review } \\
\text { article }\end{array}$ & $\begin{array}{l}\text { - Performing early detection of diseases and } \\
\text { appropriate referral } \\
\text { - Educating about hand hygiene and prevention of } \\
\text { infection } \\
\text { - Guiding patients on the differentiation of surgical } \\
\text { masks from others } \\
\text { - Screening patients with COVID-19-related } \\
\text { symptoms and performing referral }\end{array}$ \\
\hline $\begin{array}{l}\text { On the frontline against } \\
\text { COVID-19: Community } \\
\text { pharmacists contribution } \\
\text { during a public health } \\
\text { crisis [6] }\end{array}$ & $\begin{array}{l}\text { Cadogan et al. } \\
\text { March-20 }\end{array}$ & $\begin{array}{l}\text { U.K. and } \\
\text { Canada }\end{array}$ & $\begin{array}{l}\text { Review } \\
\text { article }\end{array}$ & $\begin{array}{l}\text { - Providing information about COVID-19 and } \\
\text { associated symptoms } \\
\text { - Educating patients about infection control and } \\
\text { prevention to reduce the transmission through hand } \\
\text { hygiene, social distancing, and self-isolation } \\
\text { - Maintaining pharmacy services that exist before } \\
\text { pandemic, including supplying over-the-counter } \\
\text { (OTC) medicines to patients } \\
\text { - Referral of any suspected cases of COVID-19 } \\
\text { - Arranging medication delivery services } \\
\text { - Conducting video-based consultations } \\
\text { - Maintaining medication adherence among patients }\end{array}$ \\
\hline $\begin{array}{l}\text { Sars-CoV-2 outbreak: How } \\
\text { can pharmacists help? [2] }\end{array}$ & $\begin{array}{l}\text { Al-Quteimat } \\
\text { et al. } \\
\text { March-20 }\end{array}$ & $\begin{array}{l}\text { United } \\
\text { Arab } \\
\text { Emirates }\end{array}$ & $\begin{array}{l}\text { Review } \\
\text { article }\end{array}$ & $\begin{array}{l}\text { - Providing appropriate information, advising about } \\
\text { precaution measures, and counseling } \\
\text { - Preparing information materials for the community } \\
\text { about government guidelines and any other } \\
\text { information related to the COVID-19 } \\
\text { - Informing community about the pandemic and } \\
\text { recommendations through websites, text messages, } \\
\text { and APPs alerts } \\
\text { - Organizing ask-and-answer sessions in schools and } \\
\text { community centers } \\
\text { - Providing home-delivery service of medications } \\
\text { - Providing online or phone counseling }\end{array}$ \\
\hline $\begin{array}{l}\text { Providing pharmacy } \\
\text { services during the } \\
\text { pandemic coronavirus [4] }\end{array}$ & $\begin{array}{l}\text { Cadogan et al. } \\
\text { March-20 }\end{array}$ & $\begin{array}{l}\text { U.K. and } \\
\text { Canada }\end{array}$ & $\begin{array}{l}\text { Review } \\
\text { article }\end{array}$ & $\begin{array}{l}\text { - Supplying preventive and treatment medications } \\
\text { - Establishing warning mechanisms to prevent the } \\
\text { shortage of medications or OTC medicines } \\
\text { - Providing event-driven pharmaceutical care } \\
\text { - Organizing groups of pharmacy experts and } \\
\text { pharmacists to make use of messaging APPs for } \\
\text { providing online prescription of medications and } \\
\text { consultation as well as arranging delivery services } \\
\text { - Educating the patients about rational thinking and } \\
\text { behavior during the COVID-19 pandemic }\end{array}$ \\
\hline
\end{tabular}

education delivered by the community pharmacies is based on the approaches that maintain wellness and promote healthy lifestyles through the prevention of substance abuse, smoking cessation, nutrition, and physical activity $[6,8,10,13]$.

\subsubsection{Patient and medication counseling}

Community pharmacists play a central role in ensuring medication safety and compliance across the continuum of care for a wide variety of diseases and therapeutic areas, such as coronary heart disease, 
skin cancer prevention, sexual health, mental health, diabetes, and lipid management [10,13].

The purpose of patient and medication counseling is to ensure that the patients understand the medication. Therefore, the community pharmacists should also counsel the patients about the importance of continued therapy and medication adherence at home. This requires the skill, expertise, and time of the community pharmacists and the full attention of the patient (e.g., for prescribed medications, the community pharmacist has the primary responsibility to counsel and advise the patients about the dosage and the best way to take them) $[4,6,8]$.

\subsubsection{Immunization}

The administration of injectables in community pharmacies is carried out by the trained pharmacists. This service is important to decongest other health institutions where this type of task is carried out, namely, hospitals and health centers, preventing the spread of the virus $[8,10]$.

When the vaccine against the COVID-19 becomes available publicly, the community pharmacies would probably become one of the centers for immunization. Therefore, community pharmacies will play a fundamental role in achieving high levels of immunity among people [8].

\subsubsection{Infection prevention and control}

Community pharmacies play a key role in infection control by developing and implementing internal pharmacy policies and procedures. The pharmacists advise patients about how to prevent infections, such as the influenza virus and sexually transmitted diseases $[8,10,13]$.

\subsubsection{Supply of medication, OTC, supplements, and health devices}

Community pharmacists can recommend symptom management for mild conditions and prescribe OTC medicines, supplements, and health devices for certain indications. They are also able to dispense prescribed medication and advise the patients about the dosage and side effects $[2,7,13]$.

\subsection{During the COVID-19 pandemic}

Since the outbreak of COVID-19, community pharmacies have been at the frontline of combating the disease. To ensure continued supplying of the medications to their patients while minimizing or avoiding community transmission, community pharmacies had to change the way they operate.

\subsubsection{Customer-oriented services}

Although COVID-19 is currently the main focus of the healthcare systems worldwide, people would still have to resort to healthcare services for examination and treatment when they develop other symptoms or diseases [6].

To avoid obstructing or burdening the emergency services for COVID-19 in the hospitals and health centers, the patients who have mild symptoms and conditions can have them checked and managed in the community pharmacies. For instance, in the early season of spring allergic reactions, the affected individuals can be treated with OTC medicines dispensed by the community pharmacies without having to resort to emergency consultations [6].

Despite not being able to give complete and direct treatment to the chronically ill patient, the community pharmacists play an important role by giving sufficient information regarding the prescribed medications to this particular patient group to prevent inappropriate use ofmedication[11]. The pharmacists should educate the patients on the importance of adherence to therapy so as to control chronic diseases, thereby avoiding unnecessary visits to health care institutions or hospitals [13].

\subsubsection{Non-medical prescription}

During this pandemic, community pharmacists in certain countries, for example, United Kingdom and Canada, can prescribe medications. The prescription models for community pharmacists differ from country to country and they can be classified as independent, complementary, or collaborative depending on the degree of responsibility granted to the community pharmacists by the prescribers [6]. This newly included service would definitely optimize the service process and prevent the saturation of health services with patients having mild conditions [6].

\subsubsection{Medication adherence}

During the pandemic, the community pharmacies continue to supply medication because it is 
extremely important that patients maintain their usual treatments to prevent the deterioration of the diseases. The community pharmacists also have the responsibility to inform patients about how they should administer their medication, the correct dosages, and the cares they should have $[1,4]$.

In all circumstances, especially during the pandemic, people with chronic diseases need to be reminded of their therapy, dosage, and correct administration on a daily basis (e.g., through messages or phone calls). Therefore, it is essential that all community pharmacies have the capacity to support all patients in their respective communities to ensure adherence to therapy. This will lead to more effective outcomes in promoting their health, both physical and psychological [11].

\subsubsection{Rational medication use}

In addition to dispensing the required medication, the community pharmacists also advise and recommend about the correct use and possible side effects of medications, thereby reducing any underlying risks. Encouraging the rational use of medication is a practice that goes beyond the dispensing process. It translates into the use of medication that is tailored to the individual characteristics and the needs of each patient, with the goal of minimizing medication-related problems $[4,11]$.

Therefore, the patients, especially those with chronic diseases, should be reminded that if the new medication they are going to take may have interactions with other medications, food, and natural products. The community pharmacist must explain so that the patients would comply with the prescribed dosage of medications and OTC medicines [11].

\subsubsection{Combating medication shortages}

The COVID-19 pandemic also sees shortages of prescription and OTC medication, leading to a shortage of stocks in community pharmacies $[4,6]$. Due to an increase in the sales of OTC medicines for treating the symptoms of fever, cough, and dyspnea, community pharmacists have now the additional role of assuring the availability of the medications, limiting their dispensation to those who require them the most $[4,6]$.

\subsubsection{Home-delivery service}

During the pandemic, direct delivery of medication to patients at home is a very effective service for reducing further transmission of COVID-19, particularly to older patients or those who are at risk (e.g., hypertensive, diabetic, and cardiac patients) because they are more likely to acquire the SARS-CoV-2 infection [2]. Therefore, the patients who are unable to go to the community pharmacy may receive their order at home with no additional costs during the pandemic $[6,12]$.

The community pharmacists can work together with social work volunteers to carry out the delivery of medication. However, it is highly important that before proceeding with the deliveries, they must be educated about the precautionary measures as well as the details of the patients to whom they will deliver the orders $[11,13]$.

\subsubsection{Drive-through}

Drive-through is a service offered by community pharmacies to allow the patients to quickly obtain medication without having to go inside the establishment. The patients can place the order and make payment without having to get out of the car [12].

Despite all these advantages, more convenient and faster services do not always translate into optimal patient care. This service may not deliver the same extent of care it would traditionally offer because there is no proper time for optimal community pharmacists-patients' interaction; consequently, certain patients may choose to go to other overcrowded healthcare institutes [12].

\subsubsection{Points of distribution (POD) and volunteering}

The POD are the spots where medication or vaccines are dispensed outside the community pharmacies. At the PODs, community pharmacists may encourage the patients to adhere to the therapy and urge them not to go to the hospitals for trivial matters to prevent the spread of COVID-19 [10]. In general, these PODs are set at schools, colleges, fire stations, and places of worship. The main objective of PODs is to allow access to medication and other health products by people who are less likely to go to a physical community pharmacy [10].

Both volunteers and community pharmacists who perform this type of service must be properly 
informed about the protective measures to avoid widespread transmission. In addition, the patients can be informed of the correct dosage of the medication so as to avoid visits to hospitals [8].

\subsubsection{Patient's education}

Depending on the needs of the communities, community pharmacists should provide education and consultancy services to their patients on disease prevention and the appropriate use of medication. In addition, the community pharmacists are responsible for educating the patients about the prevention of COVID-19 by urging them to wear face masks, as well as educating them on the importance of hand hygiene and the safe use of disinfection products $[7,13]$.

Educating patients to identify the symptomatic differences between a common cold, the flu, and COVID-19 is extremely important, as it helps the community know the action to be taken according to the symptoms they are experiencing. They should also explain to patients that currently, there is no effective vaccine to control this disease or any therapy that eradicates or mitigates it [13].

Pharmacies are the first place of contact in the healthcare system with the patients. Therefore, the community pharmacists also have the responsibility to educate patients about the preventive measures adopted in their respective countries or regions, the necessity of practicing social distancing, the correct use of medical masks, and the correct techniques of maintaining hand hygiene. Some of the approaches for achieving efficient patient's education include giving out flyers, reminding or alerting through the official websites of community pharmacies, as well as sending text messages and application alerts to their patients or to the whole community $[2,10]$. In addition, to raise community awareness, community pharmacies can also organize informative sessions in schools and community centers to educate the community about the necessary preventive measures. This will help at getting all important information about this pandemic to as many people as possible [2].

This coronavirus outbreak immobilized and changed the lives of many people who were advised and forced to stay at home, putting their personal and professional lives on hold. This "annulment of life" would lead to psychological stress, anxiety, and depression. Therefore, community pharmacists must pay attention to the emotional and psychological conditions of each patient by providing psychological support through psychology consultations and promoting the mental health of patients during the pandemic [13].

Community pharmacists should also encourage the public to maintain their routine lifestyle as much as possible, that is, continued compliance with work and rest times, the practice of physical exercise, and the adoption of a healthy diet [13].

\subsubsection{Online services}

At this time of pandemic, community pharmacies may reach the patients in the communities using social networks, mobile APPs, online stores, messages, and phone calls [2,13]. This may strengthen the relationship between the patients and community pharmacies and ensure that the patients do not make any unnecessary visits to healthcare institutions since the community pharmacies may offer quicker response $[2,13]$.

In addition, online pharmacies may assist patients to find pharmacies that have the medications they need, whereas mobile APPs enable them to search for different pharmacies located in their area of residence or surroundings. The patients can purchase OTC medications online and order delivery to their own home by using mobile APPs [11].

In China, for example, doctors and community pharmacists are using mobile APPs to conduct online consultations. Compared to traditional visits, this method proves to be safer for all parties. Besides, some community pharmacies in China are using a messaging app called WeChat to get closer to their patients to provide free information about medication and reduce overcrowding at the physical sites of pharmacies, thereby blocking the spread of the virus [4].

\subsection{Summary and perspectives}

In this systematic review of the literature, the services available at community pharmacies before and during the COVID-19 pandemic were reviewed. At this trying time, community pharmacies have to modify some of their services or even reinvent themselves to help the populations in need. 
To avoid the congestion in the hospitals and the spread of the disease, the community pharmacists in some countries are granted the authority of prescribing medications for patients with mild conditions so as to avoid unnecessary travel to the hospitals. The administration of injectables continues to be a sought after service offered by the community pharmacies, thereby reducing the crowds in the healthcare institutions that also offer a similar service.

In addition to the home-delivery service of medication that has already been practiced by many community pharmacies, during the COVID-19 pandemic, the pharmacists also need to promote other types of services that could reach even more people, especially the chronically ill patients and those at risk of contracting the coronavirus. The implementation of a drive-through in some countries also found some success in limiting the spread of the virus. Furthermore, community pharmacies provide patients with relevant and reliable information regarding COVID-19 and guide them to identify and manage potential cases of the COVID-19. Psychological support is also indispensable to help patients deal with the emotional impact generated by the pandemic. Therefore, capable community pharmacies should also consider providing psychological consultations to alleviate the stress and emotional impacts of the patients.

\section{Conclusion}

In addition to the normal services, the community pharmacies should consider introducing and offering additional services that aim to continuously supply medications in the face of shortages, recommend patients on the use of medications, and educate the community about the protective measures for preventing the transmission of COVID-19. These new roles and services are instrumental to alleviate the burden currently placed on the hospitals and prevent the spread of COVID-19.

\section{Acknowledgments}

The authors are grateful to the Foundation for Science and Technology (FCT, Portugal) and
FEDER under Programme PT2020 for financial support to CIMO (UID/AGR/00690/2013).

\section{Conflicts of interest}

None to declare.

\section{Author contributions}

A.M. and C.S. conceived the idea of this systematic review and wrote the paper. I.P. supervised all the steps. All authors read and approved the final version of the manuscript and agree to be held accountable for the content therein.

\section{References}

[1] Zhu, N.; Zhang, D.; Wang, W.; Li, X.; Yang, B.; Song, J.; Zhao, X.; Huang, B.; Shi, W.; Lu, R.; Niu, P.; Zhan, F.; Ma, X.; Wang, D.; Xu, W.; Wu, G.; Gao, G.F.; Tan, W.; China Novel Coronavirus Investigating and Research Team. A Novel Coronavirus from Patients with Pneumonia in China, 2019. N. Engl. J. Med., 2020, $382,727-33$.

[2] Al-Quteimat, O.M.; Amer, A.M. SARS-CoV-2 Outbreak: How can Pharmacists Help? Res. Soc. Adm. Pharm., 2020, 20, 18-20.

[3] Ministry of Health (Portugal). Health and Daily Activities: General Measures for COVID-19 Prevention and Control. Vol. 1. Available from: https://www.covid19.min-saude.pt/wp-content/uploads/2020/05/ manualvolume1-1.pdf. [Last accessed on 2020 Oct 01].

[4] Liu, S.; Luo, P.; Tang, M.; Hu, Q.; Polidoro, J.P.; Sun, S.; Gong, Z. Providing Pharmacy Services during the Coronavirus Pandemic. Int. J. Clin. Pharm., 2020, 42(2), 299-304.

[5] Shin, H.S. Empirical Treatment and Prevention of COVID-19. Infect. Chemother., 2020, 52(2), 142-53.

[6] Cadogan, C.A.; Hughes, C.M. On the Frontline against COVID-19: Community Pharmacists' Contribution during a Public Health Crisis. Res. Soc. Adm. Pharm., 2020, 20, 1-4.

[7] Oi, C.; Ung, L. Community Pharmacist in Public Health Emergencies: Quick to Action against the Coronavirus 2019-nCoV Outbreak. Res. Soc. Adm. Pharm., 2020, 16(4), 583-6.

[8] Hedima, E.W.; Adeyemi, M.S.; Ikunaiye, N.Y. Community Pharmacists: On the Frontline of Health Service against COVID-19 in LMICs. Res. Soc. Adm. Pharm., 2020, 20, 1-11.

[9] Donato, H.; Donato, M. Stages for Undertaking a Systematic Review. Acta Med. Port., 2019, 32(3), 227-35.

[10] Aruru, M.; Truong, H.A.; Clark, S. Pharmacy Emergency Preparedness and Response (PEPR) Framework for Expanding Pharmacy Professionals' Roles and Contributions to Emergency Preparedness and Response during the COVID-19 Pandemic and Beyond. Res. Soc. Adm. Pharm., 2020, 20, 2.

[11] Kretchy, I.A.; Asiedu-Danso, M.; Kretchy, J.P. Medication Management and Adherence during the COVID-19 Pandemic: Perspectives and Experiences from Low-and Middle-income Countries. Res. Soc. Adm. Pharm., 2020, $20,7$.

[12] Basheti, I.A.; Nassar, R.; Barakat, M.; Alqudah, R.; Abufarha, R.; Muqatash, T.; Saini, B. Pharmacists' Readiness to Deal with the Coronavirus Pandemic: Assessing Awareness and Perception of Roles. Res. Soc. Adm. Pharm., 2020, 20, 30418-6.

[13] Zheng, S.Q.; Yang, L.; Zhou, P.X.; Li, H.B.; Liu, F.; Zhao, R.S. Recommendations and Guidance for Providing Pharmaceutical Care Services during COVID-19 Pandemic: A China Perspective. Res. Soc. Adm. Pharm., 2020, 49, 30284-9. 